\title{
Práticas sociais híbridas: contribuições para os estudos curriculares em Educação Matemática
}

\author{
Marcio Antonio da Silva*
}

\begin{abstract}
Resumo
Neste artigo, discute-se, na perspectiva teórica curricular pós-crítica, a impossibilidade de pensar em práticas sociais universais que possam gerar prescrições curriculares centralizadoras que orientem ações a serem efetivadas nas escolas, não considerando a incerteza e a diversidade das práticas educativas, sociais e culturais. Utiliza-se o conceito de hibridação para argumentar que as próprias prescrições curriculares apresentam discursos híbridos que necessitariam de uma maior investigação, pois representam misturas e construções que defendem correntes teóricas distintas, algumas até antagônicas. Por fim, são encaminhadas considerações no sentido de buscar formas de atenuar esse imenso hiato entre as teorias contemporâneas e a "prática" curricular.

Palavras-chave: Educação Matemática; Currículo de Matemática; Hibridação.
\end{abstract}

\section{Hybrid social practices: contributions to curriculum studies in Mathematics Education}

\begin{abstract}
In this paper, we discuss in theoretical perspective post-critical curricular theory, inability to think in universal social practices that generate prescriptions centralized curriculum to guide actions to be effected in schools, not considering the uncertainty and diversity of educational practices, socials and culturals. We use the concept of hybridization to argue that curricular prescriptions have hybrid discourses that would require further investigation because they represent mixtures and buildings that advocate different theoretical currents, some even antagonistic. Finally, considerations are directed towards finding ways to mitigate this huge gap between contemporary theories and "practical" curriculum.

Keywords: Mathematics Education; Mathematics Curriculum; Hybridization.
\end{abstract}

\section{Introdução}

O objetivo deste artigo é discutir, na perspectiva teórica curricular pós-crítica, a impossibilidade de pensar em práticas sociais universais que possam ser descritas e, consequentemente, possam gerar prescrições curriculares centralizadoras que orientem ações a serem efetivadas nas escolas.

Queremos contribuir para a reflexão acerca da contradição existente entre as teorias curriculares contemporâneas que apontam para a direção da diversidade, do hibridismo e da valorização da incerteza e as políticas curriculares nacionais que determinam orientações $\mathrm{e}$ avaliações universais e padronizadas.

No entanto, mostraremos que, tanto as teorias pós-críticas, quanto os currículos prescritos apresentam, ao menos, uma característica comum: a presença de um discurso híbrido.

Para finalizar o artigo, encaminharemos nossas considerações no sentido de buscar formas de atenuar esse imenso hiato entre as teorias contemporâneas e a "prática" curricular.

\section{A centralização curricular no Brasil}

No dia quinze de setembro deste ano, a Folha de São Paulo, em seu painel Tendências e
Debates, propôs o debate em torno da seguinte questão: o Brasil deve adotar um currículo nacional único para a educação básica?

Respondendo afirmativamente à pergunta proposta, Priscila Cruz, diretora-executiva do movimento Todos Pela Educação, apresentou o discurso meritocrático cristalizado das atuais políticas neoliberais: é preciso padronizar os processos educacionais para facilitar a avaliação de alunos, professores e gestores.

Em oposição à perspectiva defendida por Priscila, a professora Dalila Andrade Oliveira, atual presidente da Associação Nacional de PósGraduação e Pesquisa em Educação (ANPEd), afirmou que a defesa de um currículo uniforme representa a volta de um discurso da elite republicana do início do século $\mathrm{XX}$ e que o currículo deve levar em conta as diferenças sociais, econômicas e culturais entre os estudantes.

Portanto, no cenário delineado por Dalila, o currículo deveria necessariamente ser (re)formulado no âmbito de cada escola e até de cada sala de aula, considerando as especificidades, as necessidades, os valores, as culturas e as práticas sociais da comunidade na qual a escola está inserida.

\footnotetext{
* Endereço eletrônico: marcio.silva@ufms.br
} 
Essa breve exposição das oposições de opiniões sobre a centralização curricular revela o antagonismo existente nas diferentes visões sobre a valorização do reconhecimento das diferentes práticas sociais presentes em um território com dimensões continentais, como é o caso brasileiro.

\section{Hibridação}

A partir daqui, faremos referência ao conceito de hibridação, difundido pelo antropólogo argentino Néstor García Canclini, e que ganha diferentes interpretações, entre elas, a defesa do reconhecimento da diversidade de práticas sociais e a construção de discursos híbridos para atender aos vários públicos para os quais as prescrições curriculares são escritas, ou seja, com a finalidade de agradar a muitos.

A obra Culturas Híbridas: estratégias para entrar e sair da modernidade, de García Canclini, foi publicada em 1989. Nela o pesquisador argentino realçou os processos de hibridação cultural ocorridos nos países latinoamericanos, sobretudo no período pós-colonial.

$\mathrm{O}$ autor se refere à mestiçagem, ao sincretismo e à crioulização como hibridações que se restringiam, respectivamente, ao processo de combinação de raças, religiões (crenças) e línguas.

O que García Canclini argumenta é que esses três tipos de "misturas culturais" são muito restritos para levar em conta as inúmeras fusões culturais que ocorrem entre estilos musicais, nas fronteiras entre países, nos meios de difusão de informação e, especialmente ligado ao nosso interesse principal, nas teorias curriculares e nos significados atribuídos ao currículo.

Por isso, García Canclini (2008) traz uma primeira aproximação do conceito de hibridação no prefácio da edição de 2001: "entendo por hibridação processos socioculturais nos quais estruturas ou práticas discretas, que existiam de forma separada, se combinam para gerar novas estruturas, objetos e práticas" (p. XIX).

É importante ressaltar que o conceito de hibridação não é novo, não só pelos usos antropológicos e linguísticos, para citar apenas dois, mas também por seu uso original relativo à Biologia, mais especificamente na genética, botânica e zoologia.

Como exemplo, podemos citar a hibridação entre espécies. No entanto, essas "misturas" são frequentemente vinculadas à esterilidade e ao exótico, provocando no imaginário popular a sensação de algo que está fora dos padrões.

O asno ou burro ou jumento é um resultado de cruzamento de espécies (cavalo com jumenta ou égua com jumento). O uso popular desses três nomes para designar um indivíduo desprovido de inteligência não é uma coincidência, mas sim uma direta vinculação com a esterilidade desse animal, condição resultante dessa hibridação.

\section{Do Modernismo ao Pós-Modernismo}

Para compreender parte dessa intolerância ao que é híbrido, é importante contextualizar os embates teóricos entre as visões modernas e pósmodernas.

O período histórico ou os movimentos teóricos ligados ao modernismo valorizam a estrutura hierárquica bem delimitada, as definições rígidas e os binarismos classificatórios antagônicos: bem versus mal, certo versus errado, alta cultura versus baixa cultura, currículo prescrito versus currículo em ação, branco versus negro, entre outros. Essa configuração teórica enaltece o purismo e considera a hibridação como uma aberração.

Já o pós-modernismo surge, entre várias outras críticas ao movimento antecedente, questionando e rompendo os binarismos, por intermédio da exposição de uma matiz de possibilidades existentes entre polos opostos, considerados como únicos pelo modernismo.

Como exemplos culturais de hibridismos, podemos citar a banda californiana Linkin Park que, não coincidentemente, deu o nome de Teoria Híbrida (Hybrid Theory) ao seu primeiro álbum e à própria banda, no final da década de 1990 , revelando a concepção dos integrantes da banda possuem a respeito do cruzamento de gêneros que envolvem a composição do seu repertório: hiphop, música eletrônica e rock pesado alternativo (DUSSEL, 2010).

Outro retrato dessa hibridação musical pode ser visto na produção do grupo de rap Brô $M C$ 's, formado por índios sul-mato-grossenses da etnia Guarani-Kaiowá. Índios cantando rap em Tupi e usando vestimentas como bonés, camisa de seleções e times de futebol e cobrindo os rostos com lenços que lembram os antigos caubóis de filmes de faroeste, parece algo inusitado, mas é a realidade desses jovens que já ganharam notoriedade ao participarem de programas de televisão transmitidos nacionalmente.

A partir desses exemplos, é quase impossível imaginar algo que não seja híbrido. A pureza é que ganha caráter exótico e gera profunda desconfiança. Até o conceito de fronteira, que na perspectiva modernista está muito mais ligado à ideia de fronteira geográfica e, portanto, matematicamente definida por uma 
lógica aristotélica (pertence ou não pertence), ganha nova configuração nas visões pós-modernas ou pós-coloniais.

Para Bhabha (1998), Hall (2003) e García Canclini (1998), a análise das fronteiras se dá na dimensão cultural e, nesta perspectiva, não faz sentido pensar em pertencimento ou não pertencimento a uma ou a outra nação, mas sim aos significados construídos, desconstruídos e reconstruídos (não necessariamente seguindo esta ordem) em espaços-tempos de fronteiras:

Penso nos currículos escolares como espaço-tempo de fronteira e, portanto, como híbridos culturais, ou seja, como práticas ambivalentes que incluem o mesmo e o outro num jogo em que nem a vitória nem a derrota jamais serão completas. Entendo-os como um espaçotempo em que estão mesclados os discursos da ciência, da nação, do mercado, os "saberes comuns", as religiosidades e tantos outros, todos também híbridos em suas próprias constituições. É um espaço-tempo em que os bens simbólicos são "descolecionados",

"desterritorializados", "impurificados", num processo que explicita a fluidez das fronteiras entre as culturas do eu e do outro e torna menos óbvias e estáticas as relações de poder (García Canclini, 1998). Defendo que, nesse híbrido que é o currículo, tramas oblíquas de poder tanto fortalecem certos grupos como potencializam resistências. Em um e outro movimento, que são parte do mesmo, permitem que a diferença apareça na negociação "com as estruturas de violência e violação que (as) produziram" (Spivak, 1994, p. 199). (MACEDO, 2006, p. 289-290).

Os comentários levantados por Macedo no excerto supracitado, com os quais concordamos, nos remetem a novas compreensões para as questões de relações de poder, identidades e diferenças.

No panorama vislumbrado a partir da perspectiva pós-crítica, nunca será possível obter um estado ideal de igualdade social, econômica e política. Por isso, o discurso que objetiva qualquer tipo de igualdade é ingênuo e idealista.

$\mathrm{O}$ conceito de classe social é desconstruído em detrimento das relações entre os subalternos marginalizados e a hegemonia cultural dominante. $\mathrm{O}$ movimento $\mathrm{e}$ as tensões direcionam-se das lutas pela igualdade social e econômica, notadamente reivindicando igualdade, para a valorização das diferenças e para o reconhecimento de identidades culturais híbridas.

Nas atuais pesquisas que levam em conta os estudos culturais não faz sentido investigar oposições binárias, como Matemática do cotidiano versus Matemática escolar, ou Matemática do índio versus Matemática do branco, mas sim o conjunto de identidades, subjetivações e significados atribuídos por diferentes participantes da pesquisa a um objeto prévia ou posteriormente definido pelo pesquisador.

As definições e categorizações rigorosamente descritas perdem sentido nesse cenário "pós". A lógica clássica e a consequente adoção do "terceiro excluído" dá lugar a lógicas heterodoxas que vão além dos binarismos, permitindo múltiplas classificações.

A palavra "laranja" pode tanto significar uma cor resultante de mistura das cores amarela e vermelha, quanto um fruto híbrido obtido a partir do cruzamento do pomelo com a tangerina. Para uma criança pode representar o entardecer. Para um político corrupto, um indivíduo cujo nome foi usado por ele para fraudes financeiras $\mathrm{e}$ comerciais.

Usamos esse exemplo simplesmente para ilustrar o quanto uma palavra pode expressar múltiplos significados, híbridos ou não. Outro ponto a se destacar é que o híbrido não é sinônimo de mistura, mas sim de algo que cria sua própria identidade. Portanto, além de mistura, é ele próprio. $\mathrm{O}$ fato de quase ninguém saber que o fruto da laranjeira é um híbrido do pomelo e da tangerina, revela o quanto esta identidade está constituída e reconhecida.

Analogamente, a Matemática escolar pode ser compreendida tanto como uma Matemática própria e totalmente desvinculada da ciência de referência, como André Chervel defendia, quanto uma Matemática transposta do saber científico que o originou, como na concepção de Yves Chevallard. Pode ser uma coisa e outra, tanto identidade construída, quanto mistura ou adaptação.

A nosso ver, a relevância das pesquisas curriculares sobre a Matemática escolar não está na origem da mesma, se é construída no contexto escolar ou transposta de um saber sábio, mas sim as identidades que são valorizadas e omitidas por esta Matemática, bem como quais são as Matemáticas hegemônicas e as subalternas.

\section{Hegemonia e Subalternidade}


Não usamos as palavras "hegemonia" e "subalternidade" no sentido de Gramsci, o qual ligava esses conceitos à ideia de oposição de classes sociais e a consequente disputa pelo poder:

[...] a ênfase de Gramsci foi na hegemonia. Também nisso residia seu maior interesse. Seus conceitos de "guerra de posições" e "guerra de movimento" compõem o cerne de uma conceituação da estratégia que implica o deslocamento das classes, segundo uma analogia com a guerra de trincheiras, para melhores pontos de observação $e$ "posições": dai a "guerra de posições" ser a batalha pela conquista da hegemonia política, pela obtenção do consentimento, a luta pelos "corações e mentes" do povo, e não meramente sua obediência transitória ou seu apoio eleitoral. A "guerra de movimento" (em oposição direta à tradição leninista de pensamento político) só pode ocorrer numa situação em que a hegemonia já tenha sido assegurada (BARRETT, 1996, p. 239).

Várias oposições a essa teoria marxista de hegemonia ganharam força após $o$ reconhecimento que a mesma ignorava questões sociais ligadas às diferenças de gêneros, etnias, raças, entre outras. Entre essas críticas, está a de Ernesto Laclau (1978) que rejeita essa ligação exclusiva entre as ideologias políticas e as de classe, nomeando essa simplificação, feita por Gramsci, de "reducionismo" (BARRET, 1996).

Nos referimos à hegemonia e à subalternidade como relações essencialmente culturais que estão em constante movimento, catalisadas pelos avanços tecnológicos e, sobretudo, pela difusão midiática global. Para García Canclini:

Uma visão mais ampla permite ver outras transformações econômicas e políticas, apoiadas em transformações culturais de longa duração, que estão dando uma estrutura diferente aos conflitos. Os cruzamentos entre o culto e o popular tornam obsoleta a representação polar entre ambas as modalidades de desenvolvimento simbólico e relativizam, portanto, a oposição política entre hegemônicos e subalternos, concebida como se se tratasse de conjuntos totalmente diferentes e sempre confrontados. $O$ que sabemos hoje sobre as operações interculturais dos meios massivos e as novas tecnologias, sobre a reapropriação que diversos receptores fazem deles, afasta-nos das teses sobre a manipulação onipotente dos grandes conglomerados metropolitanos. Os paradigmas clássicos segundo os quais foi explicada a dominação são incapazes de dar conta da disseminação dos centros, da multipolaridade das iniciativas sociais, da pluralidade de referências - tomadas de diversos territórios - com que os artistas, os artesãos e os meios massivos montam suas obras (GARCÍA CANCLINI, 2008, p. 346).

Além das características das relações hegemônico-subalternas, explicitadas no excerto supracitado, é fundamental acrescentar a isso o fato de que esses vínculos são estabelecidos de maneira múltipla e complexa, formando redes de significações.

Algo ou alguém pode, em determinado instante, agir tanto como hegemônico, quanto como subalterno. Não há, portanto, classificação única, pois os múltiplos olhares dependem das "lentes" que utilizamos para examinar tal relação:

$O$ incremento de processos de hibridação torna evidente que captamos muito pouco do poder se só registramos os confrontos $e$ as ações verticais. $O$ poder não funcionaria se fosse exercido unicamente por burgueses sobre proletários, por brancos sobre indígenas, por pais sobre filhos, pela mídia sobre os receptores. Porque todas essas relações se entrelaçam umas com as outras, cada uma consegue uma eficácia que sozinha nunca alcançaria. Mas não se trata simplesmente de que, ao se superpor umas formas de dominação sobre as outras, elas se potenciem. O que lhes dá sua eficácia é a obliquidade que se estabelece na trama. Como discernir onde acaba o poder étnico e onde começa o familiar ou as fronteiras entre o poder político e o econômico? Às vezes é possivel, mas o que mais conta é a astúcia com que os fios se mesclam, com que se passam ordens secretas e são respondidas afirmativamente (GARCÍA CANCLINI, 2008, p. 346).

Portanto, não faz sentido compreender os currículos de Matemática na perspectiva das 
classes sociais hegemônicas e subalternas, nem como essas últimas podem ser consideradas e conduzidas a uma posição de igualdade em relação às primeiras, mas sim compreender os significados, as relações estabelecidas, as modificações ocorridas e os interesses que emergem nessa teia complexa costurada culturalmente, por intermédio da (re)construção de identidades que são, simultaneamente, expressivas e efêmeras.

\section{Identidades Culturais}

Temos como hipótese que a identidade da Matemática hegemônica é masculina, europeia, heterossexual e branca. Nossa hipótese é reforçada a cada livro de História da Matemática que lemos e a cada filme que assistimos, os quais possuem personagens que têm a Matemática como profissão ou como preferência de estudo.

Mesquita (2004) traz uma convergência nos padrões identitários de professores de Matemática, a partir da análise de quatro filmes hollywoodianos. Como resultado, afirma que:

\section{[...] Hollywod conduz os espectadores de seus filmes para uma abreviação identitária do professor de matemática - homens, tímidos, obsessivos, arrogantes, competitivos, indiferentes frente às relações interpessoais, racionais, patéticos, desajeitados, isolados, problemáticos, exibicionistas perante o conhecimento matemático, disciplinados e reservados. (p. 6).}

Provavelmente as conclusões não seriam muito diferentes se analisássemos os matemáticos mais citados em livros de História da Matemática de autores tradicionais, como Eric Bell, Dirk Struik, Carl Boyer, Howard Eves, Florian Cajori e Victor Katz.

Quando o matemático escocês Eric Temple Bell publicou os seus dois volumes de Men of Mathematics, em 1937, ele não imaginava (ou talvez imaginasse) o quanto sua infindável lista de homens que contribuíram para o desenvolvimento da Matemática, ao longo de séculos, contribuiu para desenhar uma identidade masculina a essa ciência.

Paulatinamente, esse cenário vem se alterando, em parte devido à publicação de obras que revelam o trabalho determinante de algumas mulheres para a evolução da Matemática.

Dentre essas mulheres, podemos citar a russa Sofia Kovalevskaya, que viveu no século XIX, foi aluna de Weierstrass e trouxe várias contribuições para a Matemática, notadamente para as funções abelianas e equações diferenciais parciais, incluindo a demonstração do Teorema Cauchy-Kovalevskaya (AUDIN, 2011). Interessante e curioso notar que Kovalevskaya é a única mulher na lista dos "homens da Matemática" de Bell.

Emmy Noether é outra grande matemática do início do século passado, considerada a mãe da Álgebra Moderna (TENT, 2008). Essas duas mulheres e muitas outras também são citadas na clássica obra de Olsen (1974) que provoca Bell com o título Women in Mathematics.

Deslocando-se da tradição matemática europeia, autores como Selati \& Bangura (2011), Plofker (2009) e Martzloff (1997) enaltecem, respectivamente, a matemática africana, indiana $\mathrm{e}$ chinesa.

A partir dessas hipóteses, defendemos a tese de que a diversidade de práticas sociais, incluindo as hegemônicas, deve ser valorizada no contexto escolar, rompendo paradigmas da excessiva valorização de alguns poucos estereótipos culturais em detrimento de outros.

O que está em jogo é o reconhecimento, no contexto escolar, de identidades sociais e culturais que são tradicionalmente subjugadas. Aliás, talvez não seja mais o caso de se pesquisar as identidades, mas de "deslocar o objeto de estudo da identidade para a heterogeneidade e a hibridação interculturais (Goldberg)" (GARCÍA CANCLINI, 2008, p. XXIII).

Esses processos de hibridações interculturais são estimulados pelo crescente uso de recursos tecnológicos para difusão de informações, ideias e culturas:

A hibridação, de certo modo, tornou-se mais fácil e multiplicou-se quando não depende dos tempos longos, da paciência artesanal ou erudita e, sim, da habilidade para gerar hipertextos e rápidas edições audiovisuais ou eletrônicas. Conhecer as inovações de diferentes países e a possibilidade de misturá-las requeria, há dez anos [o autor escreveu este excerto em 2001], viagens freqüentes, assinaturas de revistas estrangeiras e pagar avultadas contas telefônicas; agora se trata de renovar periodicamente o equipamento de computador e ter um bom servidor de internet. (GARCÍA CANCLINI, 2008, p. $X X X V I)$.

No campo curricular, como veremos a seguir, a facilidade de se propagar informações por intermédio de novas mídias, também 
possibilitou recontextualizações de discursos diversos.

\section{Híbridos Curriculares}

Atualmente, há uma relativa concordância sobre a impossibilidade de se definir currículo, dada a multiplicidade de elementos que envolvem esse conceito, bem como uma gama complexa de contextos abrangidos por ele.

Uma possibilidade, a nosso ver mais coerente, é se referir ao próprio currículo como um híbrido:

A própria noção de currículo pode ser considerada como um híbrido, se a pensamos como o resultado de uma alquimia que seleciona a cultura e a traduz a um ambiente e uma audiência particulares (Bernstein, 1990; Popkewitz, 1998). Os discursos curriculares também têm sido estudados como híbridos que combinam distintas tradições $e$ movimentos disciplinares, construindo coalizões que dão lugar a consensos particulares (DUSSEL, 2010, p. 70).

As políticas curriculares, por sua vez, também não estão imunes a essas influências culturais caracterizadas pelas hibridações.

Nos textos que definem as diretrizes curriculares pelo mundo afora, notamos aparentes contradições em vários discursos possíveis:

Discursos como os de valorização das competências, do currículo integrado, da gestão escolar descentralizada, da avaliação como garantia de qualidade podem ser encontrados em diferentes políticas no mundo e sua presença é justificada pela ação do contexto de influência (LOPES, 2004, p. 112).

Essas teorias supostamente divergentes acabam por produzir um discurso híbrido que, assim como todos os outros discursos curriculares, não é neutro.

Em Silva (2009) identificamos, na análise da Proposta Curricular de Matemática do Estado de São Paulo de 2008, dois discursos curriculares aparentemente antagônicos: o currículo por competências e o currículo crítico.

Salientamos, na época, "o hibridismo existente no próprio conceito de competências, pois ora se utiliza o aspecto cognitivoconstrutivista da tradição francesa, ora se faz uso da configuração comportamental, advinda da tradição americana" (p. ??).

Lopes (2002) encontrou um discurso curricular híbrido nos Parâmetros Curriculares Nacionais para o Ensino Médio. Por intermédio da análise do conceito de contextualização que aparece em tal documento oficial, a autora defende:

[...] que o discurso dos PCNEM apresenta ambigüidades de forma a se legitimar junto a diferentes grupos sociais, sejam aqueles que trabalharam em sua produção ou aqueles que trabalham na sua implementação $e$ análise. Para produção de uma proposta curricular como a dos PCNEM, são apropriados e hibridizados discursos acadêmicos, ressignificando-os de forma $a$ atender às finalidades educacionais previstas no momento atual. Defendo, igualmente, que as finalidades educacionais dos PCNEM visam especialmente formar para a inserção social no mundo produtivo globalizado. Em decorrência dessas finalidades é que defendo uma postura crítica em relação a esses parâmetros (LOPES, 2002, p. 389).

Essas ressignificações ou recontextualizações, na expressão usada por Bernstein (1996), hibridizam discursos curriculares internacionais na tentativa de obter, entre outras coisas, ampla legitimação discursiva.

Essa grande amplitude pode ser justificada, em parte, pela empatia induzida ao se ler algo que se defende, mesmo estando presente em meio a várias outras teorias antagônicas a esta.

Assim, orientações curriculares geralmente são genéricas e misturam discursos defendidos por escolas teóricas distintas: o desenvolvimento de competências, a eficiência, a valorização dos objetivos, a educação para a igualdade e para a justiça social, a celebração da diversidade, entre outras.

Cabe aos pesquisadores de currículos não mais apenas identificar ou "desmascarar" esses discursos híbridos, mas também compreender suas intenções ocultas. Para Lopes (2005):

$\mathrm{Na}$ investigação das políticas de currículo, cabe entender os processos materiais e discursivos que favorecem tais consensos e finalidades, bem como as zonas de escape que são favorecidas. Do ponto de vista material, há investimentos em certas linhas e não em outras, 
discursivamente há a legitimação de certos discursos e não outros, muitas vezes favorecida pela associação desses textos com matrizes de pensamento que circulam em diferentes grupos sociais $e$ mesmo nos meios educacionais. Assim como é necessário considerar como as dimensões discursiva e material também se associam (LOPES, 2005, p. 60).

Todas essas possibilidades de pesquisa revelam uma crescente valorização de procedimentos metodológicos relacionados à análise de discurso e à bricolagem em detrimento daqueles que utilizam categorizações definidas $a$ priori e análise de conteúdo.

\section{Considerações finais}

Como anunciado no início deste artigo, nossa intenção foi elaborar uma construção argumentativa contra a ideia de práticas sociais universais. Ao contrário, podemos pensar em práticas sociais híbridas, vivenciadas $\mathrm{e}$ produzidas em contextos culturais plurais, nos quais os conceitos de hegemonia, de nação com fronteiras bem delimitadas e de ideologia são relativizados e atenuados por tendências culturais contemporâneas.

Nesse quadro que se delineia atualmente, não é apropriado pensar em orientações curriculares centralizadoras, as quais são constituídas, em sua maioria, por listas infindáveis de conteúdos rigidamente sequenciados e com suas respectivas expectativas de aprendizagem esperadas dos estudantes bem definidas, tudo meticulosamente engendrado em função de avaliações em larga escala.

Por outro lado, pela experiência que obtivemos com o trabalho na formação inicial e continuada de professores de Matemática, sabemos que os docentes, muitas vezes, anseiam por essas listas e por instruções diretivas. Então, o que fazer?

É fundamental que haja uma aproximação entre pesquisadores e professores, estreitando relações e diminuindo as distâncias que separam as "academias" das escolas. Essa distância não é só física, mas também teórica. O hiato que há entre a teoria curricular valorizada no campo cientifico e as práticas educativas é enorme.

Há que se buscar meios para que cheguem até os professores discussões como as feitas neste artigo, valorizando a pluralidade social e cultural, não como mera celebração das diferenças, mas sim com uma visão crítica sobre a necessidade de desenredar os fios que constituem essa complexa e rica teia de significações que o currículo possui.

A nosso ver, o conceito de hibridação dos estudos culturais, trazido para os estudos curriculares, é uma possibilidade de compreender criticamente os discursos subjacentes, descortinando intenções ocultas, relações de poder e planejamentos que valorizam excessivamente a performance em detrimento do enaltecimento da construção de valores humanos, os quais são incomensuráveis.

O professor deve conhecer, debater, questionar, e, porque não dizer, hibridizar essas e outras perspectivas que podem enriquecer suas práticas.

As teorias curriculares se desenvolveram com rapidez exponencial no último século, porém a escola continua reproduzindo padrões fabris da época da Revolução Industrial.

É recomendável que aceleremos o ritmo de formação de formadores de professores, pois só assim poderemos democratizar o conhecimento científico curricular, que hoje parece estar reduzido a um grupo pequeno de pesquisadores que avançam rapidamente sem olhar para trás, ignorando a possibilidade de, um dia, ficarem sozinhos e serem compreendidos apenas por seus pares. Será que esse dia já chegou? Talvez.

\section{Referências Bibliográficas}

AUDIN, Michèle. Remembering

Sofia

Kovalevskaya. Londres: Springer, 2011.

BARRET, Michèle. Ideologia, Política e Hegemonia: de Gramsci a Laclau e Mouffe. In: ZIZEK, Slavoj (Org.). Um Mapa da Ideologia. Tradução de: Vera Ribeiro. Rio de Janeiro: Contraponto, 1996.

BERNSTEIN, Basil. A Estruturação do Discurso Pedagógico: Classe, Códigos e Controle. Petrópolis: Vozes, 1996.

BHABHA, Homi. O Local da Cultura. Tradução de: Myriam Ávila, Eliana Lourenço de Lima Reis, Gláucia Renate Gonçalves. Belo Horizonte: Editora UFMS, 1998.

DUSSEL, Inés. O Currículo Híbrido: domesticação ou pluralização das diferenças? In: LOPES, Alice Casimiro; MACEDO, Elizabeth (Orgs.). Currículo: debates contemporâneos. 3. ed. São Paulo: Cortez: 2010. 
GARCÍA CANCLINI, Nestor. Culturas Híbridas: estratégias para entrar e sair da modernidade. Tradução de: Ana Regina Lessa e Heloísa Pezza Cintrão. Tradução da introdução: Gênese Andrade. 4.e., 3.reimpr. São Paulo: Editora da Universidade de São Paulo, 2008.

HALL, Stuart. Da Diáspora: identidades e mediações culturais. Tradução de: Adelaide La Guardia Resende et al. Belo Horizonte: Editora UFMG, 2003.

LACLAU, Ernesto. Política e ideologia na teoria marxista. Rio de Janeiro: Paz e Terra, 1978.

LOPES, Alice Casimiro. Os parâmetros curriculares nacionais para o ensino médio e a submissão ao mundo produtivo: o caso do conceito de contextualização. Educação \& Sociedade, v. 23, n. 80, p. 389-404, 2002.

LOPES, Alice Casimiro. Políticas curriculares: continuidade ou mudança de rumos? Revista Brasileira de Educação, v. 1, n. 26, p. 109-118, 2004.

LOPES, Alice Casimiro. Política de currículo: recontextualização e hibridismo. Currículo sem Fronteiras, v. 5, n. 2, p. 50-64, 2005.
MACEDO, Elizabeth. Currículo como espaçotempo de fronteira cultural. Revista Brasileira de Educação, v.11, n.32, p. 285-296, 2006.

MARTZLOFF, Jean-Claude. A History of Chinese Mathematics. Berlim: Springer-Verlag, 1997.

MESQUITA, Carla Gonçalves Rodrigues. O professor de matemática no cinema: cenários de identidades e diferenças. $27^{\mathrm{a}}$ reunião da ANPED. Anais... Caxambú. 2004.

OSEN, Lynn M. Women in mathematics. Massachusetts: The MIT Press, 1974.

PLOFKER, Kim. Mathematics in India. Princeton: Princeton University Press, 2009.

SETATI, Mamokgethi; BANGURA, Abdul Karim. African Mathematics: From Bones to Computers. Lanham: University Press of America, 2011.

SILVA, Marcio Antonio. Currículo por competências ou currículo crítico? Uma análise da Proposta Curricular do Estado de São Paulo. Boletim GEPEM, v. 55, p. 113-132, 2009.

TENT, Margaret. Emmy Noether: the mother of modern algebra. Wellesley, Massachusetts: A. K. Peters, 2008.

\section{Sobre o autor:}

Marcio Antonio da Silva é licenciado em Matemática (Universidade de São Paulo, 1998), mestre em Educação Matemática (Pontifícia Universidade Católica de São Paulo, 2004) e doutor em Educação Matemática (Pontifícia Universidade Católica de São Paulo, 2009). Atualmente é Professor Adjunto, lotado no Centro de Ciências Exatas e Tecnologia da Universidade Federal de Mato Grosso do Sul (Campo Grande, MS), professor permanente do Programa de Pós-Graduação em Educação Matemática e do Programa de PósGraduação em Educação, na mesma instituição. Também é líder do GP100 (GPCEM - Grupo de Pesquisa Currículo e Educação Matemática), criado em agosto de 2012. 